\title{
Antagonism of stem cell factor/c-kit signaling attenuates neonatal chronic hypoxia-induced pulmonary vascular remodeling
}

\author{
Karen C. Young ${ }^{1,2,3}$, Eneida Torres ${ }^{1,2}$, Dorothy Hehre ${ }^{1,2}$, Shu Wu ${ }^{1,2}$, Cleide Suguihara ${ }^{1,2}$ and Joshua M. Hare ${ }^{3,4}$
}

BACKGROUND: Accumulating evidence suggests that c-kit-positive cells are present in the remodeled pulmonary vasculature bed of patients with pulmonary hypertension (PH). Whether stem cell factor (SCF)/c-kit-regulated pathways potentiate pulmonary vascular remodeling is unknown. Here, we tested the hypothesis that attenuated c-kit signaling would decrease chronic hypoxia-induced pulmonary vascular remodeling by decreasing pulmonary vascular cell mitogenesis.

METHODS: Neonatal FVB/NJ mice treated with nonimmune IgG (placebo), or c-kit neutralizing antibody (ACK2) as well as c-kit mutant mice (WBB6F1-Kit ${ }^{W-/ /+}$ ) and their congenic controls, were exposed to normoxia $\left(\mathrm{FiO}_{2}=0.21\right)$ or hypoxia $\left(\mathrm{FiO}_{2}=\right.$ 0.12 ) for $2 w k$. Following this exposure, right ventricular systolic pressure (RVSP), right ventricular hypertrophy (RVH), pulmonary vascular cell proliferation, and remodeling were evaluated. RESULTS: As compared to chronically hypoxic controls, c-kit mutant mice had decreased RVSP, RVH, pulmonary vascular remodeling, and proliferation. Consistent with these findings, administration of ACK2 to neonatal mice with chronic hypoxia-induced PH decreased RVSP, RVH, pulmonary vascular cell proliferation, and remodeling. This attenuation in PH was accompanied by decreased extracellular signal-regulated protein kinase (ERK) 1/2 activation.

CONCLUSION: SCF/c-kit signaling may potentiate chronic hypoxia-induced vascular remodeling by modulating ERK activation. Inhibition of c-kit activity may be a potential strategy to alleviate $\mathrm{PH}$.

N eonatal chronic hypoxia-induced pulmonary hypertension $(\mathrm{PH})$ is characterized by vascular pruning and profound remodeling of peripheral pulmonary vessels (1). These pulmonary vascular changes mimic those seen in infants with severe bronchopulmonary dysplasia and are a significant cause of morbidity and mortality. Currently, mechanistic pathways remain unclear and there are few efficacious therapies.

CD117 or c-kit, a tyrosine kinase receptor encoded at the $\mathrm{W} /$ Kit locus (2), is mainly utilized as a stem cell marker $(3,4)$.
Yet this receptor is also expressed on myocardial tissue, mast cells, dendritic cells, systemic vascular smooth muscle cells, epithelial cells, and fetal pulmonary vascular endothelial cells $(2,5-7)$. The ligand for c-kit is stem cell factor (SCF). Encoded at the steel locus on murine chromosome 10, SCF is expressed by several cells, including endothelial cells and lung fibroblasts (8). Interestingly, although recent studies have demonstrated increased c-kit ${ }^{\text {pos }}$ cells in the media and adventitia of remodeled pulmonary arterioles, the role of SCF/c-kit signaling in the pathogenesis of $\mathrm{PH}$ is unclear (9-11).

It is however known that binding of SCF to c-kit results in dimerization of the receptor, with subsequent activation of its intrinsic tyrosine kinase and phosphorylation of its tyrosine residues (12). These phosphorylated sites are known to function as docking stations for several signal transduction proteins which induce the activation of signaling pathways, believed to be responsible for $\mathrm{SCF} / \mathrm{c}$-kit role in cell differentiation, survival, and proliferation $(13,14)$. This latter process is particularly relevant in the context of $\mathrm{PH}$ as pulmonary vascular proliferation is one of the main mechanisms postulated to contribute to the pulmonary vascular remodeling evidenced in this disease.

Consistent with this theory, other investigators have suggested that c-kit and SCF play important roles in systemic vascular remodeling. The expression of c-kit and SCF were increased in atherosclerotic vessels (5) and mice with defective c-kit signaling (c-kit mutant mice) had decreased systemic vascular remodeling following injury $(14,15)$. Moreover, administration of imatinib mesylate (a nonspecific c-kit antagonist) improved pulmonary vascular resistance as well as walking distance in idiopathic $\mathrm{PH}$ (16).

This present study sought to test the hypothesis that activation of c-kit signaling potentiates neonatal chronic hypoxiainduced pulmonary vascular remodeling by increasing pulmonary vascular cell proliferation. Using a chronic hypoxia in vivo model of neonatal $\mathrm{PH}$, we show that neonatal hypoxic c-kit mutant mice exhibit decreased $\mathrm{PH}$, right ventricular hypertrophy $(\mathrm{RVH})$, pulmonary vascular cell proliferation, and

'Department of Pediatrics, University of Miami Miller School of Medicine, Miami, Florida; ${ }^{2}$ Batchelor Children's Research Institute, Department of Pediatrics, University of Miami Miller School of Medicine, Miami, Florida; ${ }^{3}$ The Interdisciplinary Stem Cell Institute, University of Miami Miller School of Medicine, Miami, Florida; ${ }^{4}$ Department of Medicine, University of Miami Miller School of Medicine, Miami, Florida. Correspondence: Karen C. Young (Kyoung3@med.miami.edu)

Received 8 May 2015; accepted 7 October 2015; advance online publication 3 February 2016. doi:10.1038/pr.2015.275 
remodeling as compared to control hypoxic mice. In addition, we show that antagonism of c-kit attenuated neonatal chronic hypoxia-induced pulmonary vascular proliferation and remodeling. Further questioning to ascertain the mechanisms by which c-kit may participate in chronic hypoxia-induced pulmonary vascular remodeling revealed that SCF/c-kit signaling increased neonatal pulmonary vascular smooth muscle cell proliferation by augmenting extracellular signal-regulated protein kinase (ERK) 1/2 activation. These findings provide important insight into the involvement of SCF/c-kit signaling in the pathogenesis of $\mathrm{PH}$.

\section{RESULTS}

SCF and c-kit Expression in Remodeled Pulmonary Arterioles of Mice With PH

We first sought to ascertain whether the expression of c-kit and its ligand, SCF, was increased in the pulmonary arterioles of neonatal $\mathrm{FVB} / \mathrm{NJ}$ mice with chronic hypoxia-induced $\mathrm{PH}$ (Figure 1a-d). Newborn FVB/NJ mice were exposed to $2 \mathrm{wk}$ of normobaric normoxia or hypoxia. Following this exposure, pulmonary arterioles were dissected. There was a significant increase in the protein expression of c-kit (1.5-fold, $P<0.03)$, SCF (1.5-fold, $P<0.001$ ), and phosphorylated c-kit (twofold, $P<0.002$ ) in the pulmonary arterioles of mice with $\mathrm{PH}$ (Figure 1a-c). Immunofluorescent staining revealed that c-kit was expressed on pulmonary vascular endothelial, medial, and adventitial cells (Figure 1d).

\section{Antagonism of SCF/c-kit Signaling Attenuates Pulmonary Vascular Remodeling}

We next exposed neonatal mice to chronic hypoxia or normoxia from postnatal day 1-14 and then randomly assigned them to receive daily i.p. injections of a neutralizing c-kit antibody (ACK2) or placebo (PL) from postnatal day 7-14. As compared to normoxia, chronically hypoxic PL mice had a significant increase in right ventricular systolic pressure (RVSP; $15 \pm 1$ vs. $28 \pm 4 \mathrm{~mm} \mathrm{Hg}$ : room air (RA) vs. hypoxia-PL; $P<$ $0.001)$, ratio of the weight of right ventricle to the left ventricle $+\operatorname{septum}(\mathrm{RV} / \mathrm{LV}+\mathrm{S} ; 0.3 \pm 0.1$ vs. $0.5 \pm 0.1$ : RA vs. hypoxiaPL; $P<0.001$ ), pulmonary vascular cell remodeling, and pulmonary vascular cell proliferation (Figure $2 \mathrm{a}-\mathbf{f}$ ). In contrast, as compared to hypoxia-PL-treated mice, the administration of ACK2 to mice with $\mathrm{PH}$ decreased right ventricular RVSP ( $28 \pm 4$ vs. $21 \pm 2 \mathrm{~mm} \mathrm{Hg}$ : hypoxia-PL vs. hypoxia-ACK2; $P<0.02), \mathrm{RV} / \mathrm{LV}+\mathrm{S}(0.5 \pm 0.1$ vs. $0.4 \pm 0.1$ : hypoxia-PL vs. hypoxia-ACK2; $P<0.01)$, pulmonary vascular cell remodeling, and pulmonary vascular cell proliferation (Figure $2 \mathbf{a}-\mathbf{f}$ ), suggesting that antagonism of SCF/c-kit signaling can attenuate $\mathrm{PH}$.

Given that neonatal exposure to chronic hypoxia negatively impacts lung alveolarization, we evaluated the effect of ACK2 on lung alveolarization by measuring mean linear intercept. Normoxic mice which received ACK2 had a trend for worsened alveolarization, evidenced by increased mean linear intercept (36 \pm 5 vs. $41 \pm 5 \mu \mathrm{m}$ : RA-PL vs. RA-ACK2; $P<0.06, n=5$ / group). Surprisingly, hypoxia- ACK2 mice had significantly lower mean linear intercept as compared to hypoxia-PL mice ( $49 \pm 3$ vs. $40 \pm 6 \mu \mathrm{m}$ : hypoxia-PL vs. hypoxia-ACK2; $P<0.03$ ), suggesting that SCF/c-kit antagonism may improve alveolarization in neonatal hypoxic mice with PH (Figure 3a,b). This improvement in lung alveolarization was however not accompanied by an increase in lung vascular density (6 \pm 3 vs. $6 \pm 1$ vessels/high-power field: hypoxia-PL vs. hypoxia-ACK2; Figure 3c).

\section{c-Kit Mutant Mice Have Decreased Susceptibility to Chronic Hypoxia-Induced $\mathrm{PH}$}

Next, we questioned whether neonatal c-kit mutant mice would have decreased susceptibility to developing chronic hypoxia-induced $\mathrm{PH}$. The c-kit mutant mice utilized in this study have the $\mathrm{W}-\mathrm{v}$ mutation which is a missense mutation in the kinase domain of the c-kit coding sequence. During normoxia, there was no difference in RVSP, RVH, pulmonary vascular remodeling nor the pulmonary vascular proliferative index between the control and the mutant mice (Figure 4a-f). Moreover, while exposure to chronic hypoxia resulted in a significant increase in RVSP $(20 \pm 1$ vs. $30 \pm 5 \mathrm{~mm} \mathrm{Hg}$ : RA control vs. hypoxia control; $P<0.001), \mathrm{RV} / \mathrm{LV}+\mathrm{S}$, pulmonary vascular cell proliferation, and remodeling in the control mice, these changes were significantly attenuated in the c-kit mutant mice (Figure 4a-f).

\section{SCF/c-kit Signaling Modulates Pulmonary Artery Smooth Muscle Proliferation by Regulating ERK1/2 Activation}

Given evidence suggesting that chronic hypoxic exposure may increase extracellular signal-regulated protein kinase (ERK)-mediated signaling and that the latter may be important in hypoxia-induced pulmonary vascular cell proliferation $(17,18)$, we questioned whether SCF/c-kit regulates pulmonary vascular cell proliferation by activating the ERK1/2 signaling pathway. As compared to normoxic mice, control mice exposed to chronic hypoxia had significantly increased expression of $\mathrm{p}$-ERK1/2 (Figure 5a). In contrast, p-ERK1/2 expression was unchanged in chronically hypoxic c-kit mutant mice (Figure 5a). Similarly, while PL-treated hypoxic neonatal mice had an increase in ERK1/2 activation, administration of ACK2 to hypoxic mice decreased ERK1/2 activation (Figure 5b). These findings suggest that c-kit may regulate pulmonary vascular cell proliferation by regulating ERK signaling.

\section{SCF Increases Pulmonary Artery Smooth Muscle Cell Proliferation by ERK1/2 Pathway}

In order to ascertain whether SCF/c-kit signaling modulates pulmonary artery smooth muscle (PASM) cell proliferation by activating the ERK1/2 pathway, we next evaluated whether a selective ERK1/2 antagonist, FR180204, could suppress SCFinduced PASM cell proliferation. PASM cells were isolated from neonatal mice and exposed to varying doses of SCF. We first demonstrated that unstimulated neonatal PASM cells do express c-kit (Figure 6a) and exposure of PASM cells to $100 \mathrm{ng} /$ $\mathrm{ml} \mathrm{SCF}$ not only increased the gene expression of c-kit (Figure 6a) but also caused an increase in p-ERK $1 / 2$ expression 
a

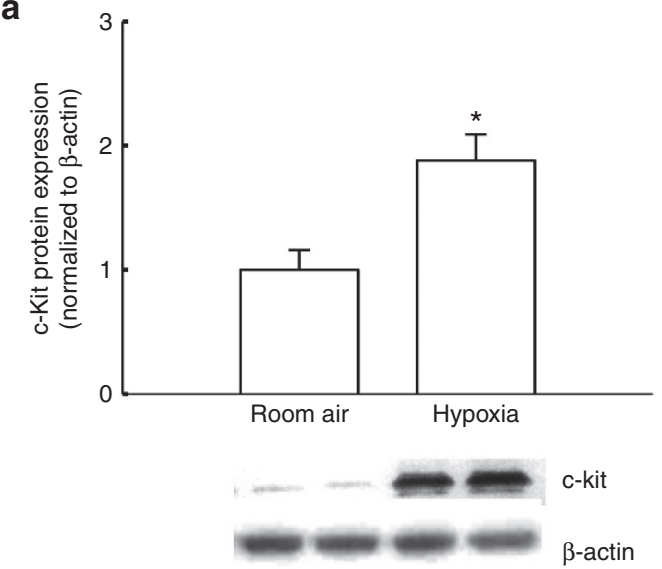

C

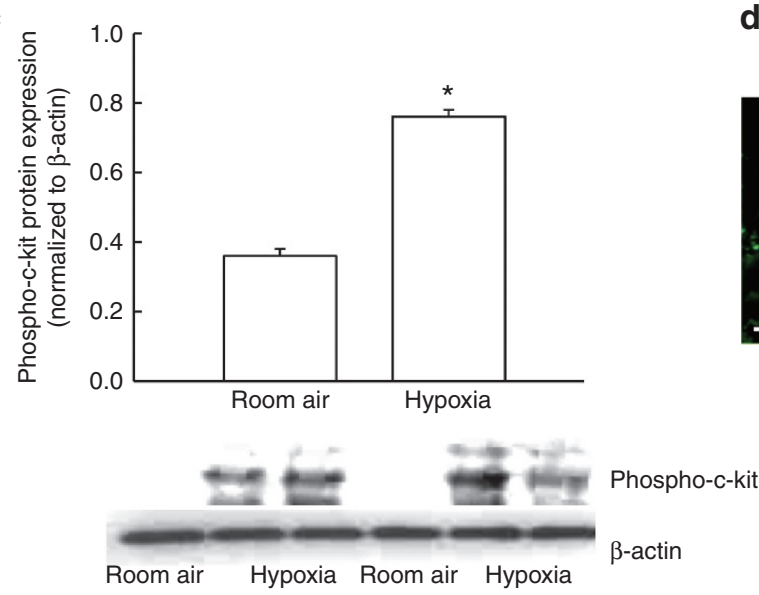

b

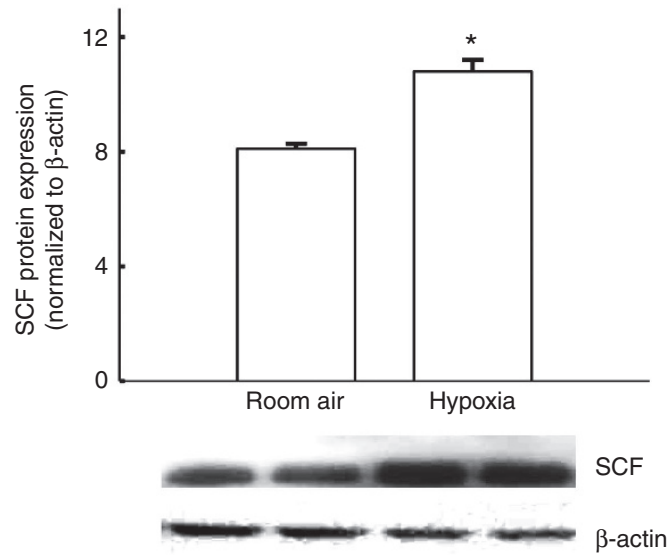

d
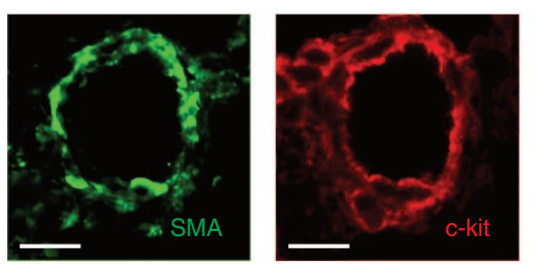

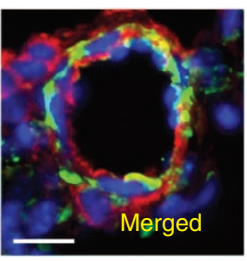

Figure 1. SCF and c-kit expression in the pulmonary arterioles of mice with chronic hypoxia-induced pulmonary hypertension. (a) Increased c-kit protein expression in the pulmonary arterioles of neonatal mice exposed to $14 \mathrm{~d}$ of hypoxia ( ${ }^{*} P<0.03$ : room air vs. hypoxia; $n=5 /$ group). c-Kit expression is normalized to $\beta$-actin. (b) Increased SCF protein expression in the pulmonary arterioles of neonatal mice exposed to $14 \mathrm{~d}$ of hypoxia $(* P<0.001$ : room air vs. hypoxia; $n=5$ /group). SCF expression is normalized to $\beta$-actin. (c) Increased phosphorylated c-kit protein expression in the pulmonary arterioles of neonatal mice exposed to $14 \mathrm{~d}$ of hypoxia $\left({ }^{*} P<0.002\right.$ : room air vs. hypoxia; $n=5 /$ group). Phosphorylated c-kit expression is normalized to $\beta$-actin. (d) Lung sections stained with $\alpha$-SMA (green) and c-kit antibodies (red) demonstrating c-kit-positive cells in the endothelium, media (yellow staining), and adventitia of the remodeled pulmonary vessel. Original magnification $\times 400$. Bar $=25 \mu \mathrm{m}$. SCF, stem cell factor; SMA, smooth muscle actin.

(Figure 6b). These findings were accompanied by an increase in the percentage of Ki67pos PASM cells $(13.4 \pm 3$ vs. $50 \pm 12 \%$ : SCF $0 \mathrm{ng} / \mathrm{ml}$ vs. SCF $100 \mathrm{ng} / \mathrm{ml} ; P<0.02$ ), (Figure $6 \mathrm{c}, \mathrm{d}$ ). Confirmatory findings with a BrdU Colorimetric Assay also demonstrated that PASM cells which were pretreated with vehicle and subsequently exposed to SCF $100 \mathrm{ng} / \mathrm{ml}$ had increased BrdU incorporation as compared to vehicle alone (Figure 6e). In contrast, SCF-exposed PASM cells which were pretreated with the ERK1/2 antagonist had suppressed BrdU incorporation (Figure 6e). Together, this suggests that SCF/ckit signaling may modulate PASM cell proliferation by regulating the ERK1/2 pathway.

\section{DISCUSSION}

The present study provides novel insight into the role of SCF/ckit signaling in the pathogenesis of chronic hypoxia-induced pulmonary vascular remodeling. We show that the expression of SCF and c-kit are increased in the pulmonary arteries of neonatal mice with $\mathrm{PH}$ and furthermore that neonatal mice with defective c-kit signaling have decreased chronic hypoxia-induced pulmonary vascular remodeling and proliferation. In addition, we demonstrate that inhibition of SCF/ckit signaling attenuates neonatal chronic hypoxia-induced pulmonary vascular remodeling and decreases activation of the ERK1/2 pathway in PASM cells. Taken together, our present data not only demonstrates a mechanism by which $\mathrm{SCF} / \mathrm{c}$-kit signaling participates in chronic hypoxia-induced pulmonary vascular remodeling but it also provides a foundation to generate new therapies.

Prior investigators have demonstrated the presence of c-kitpositive cells in remodeled pulmonary arterioles of animals and humans with PH. Davie et al. demonstrated increased c-kit ${ }^{\text {pos }}$ cells in the vasa vasorum of the pulmonary artery adventitia of hypoxic calves and suggested that c-kitpos cells in the vasa vasorum may contribute to pulmonary vascular remodeling by augmenting pulmonary artery adventitia neovascularization (9). Additionally, Frid et al. demonstrated the presence of c-kit ${ }^{\text {pos }}$ cells in the pulmonary artery media of hypoxic calves and showed that these cells had highly augmented proliferative, migratory, invasive, and mitogenic capabilities (19). In our 


\section{Articles | Young et al.}

a

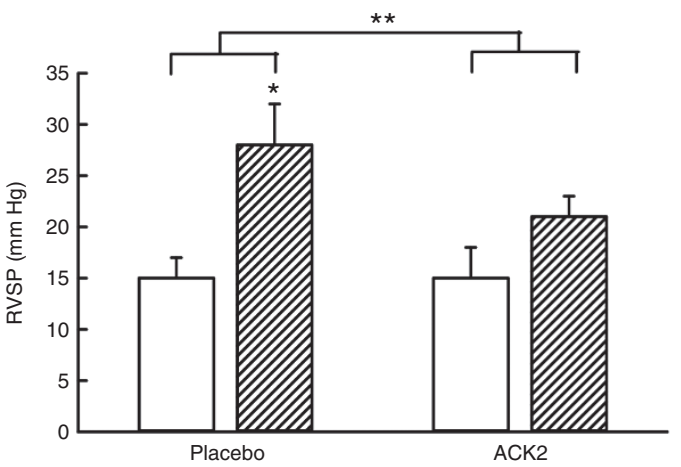

C
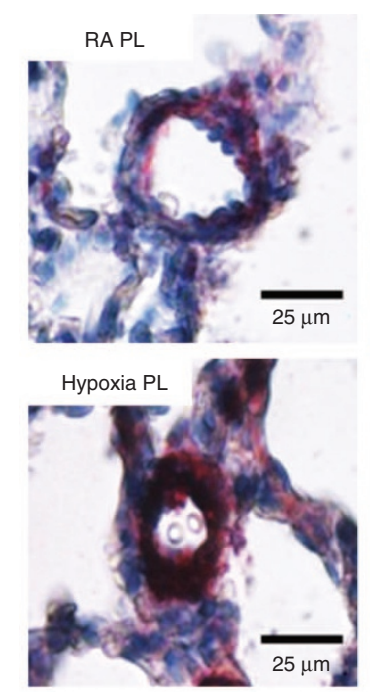

e
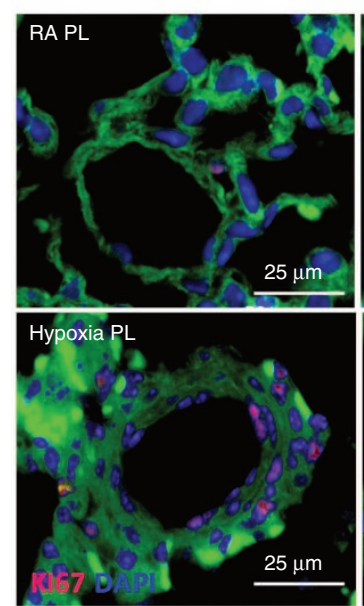
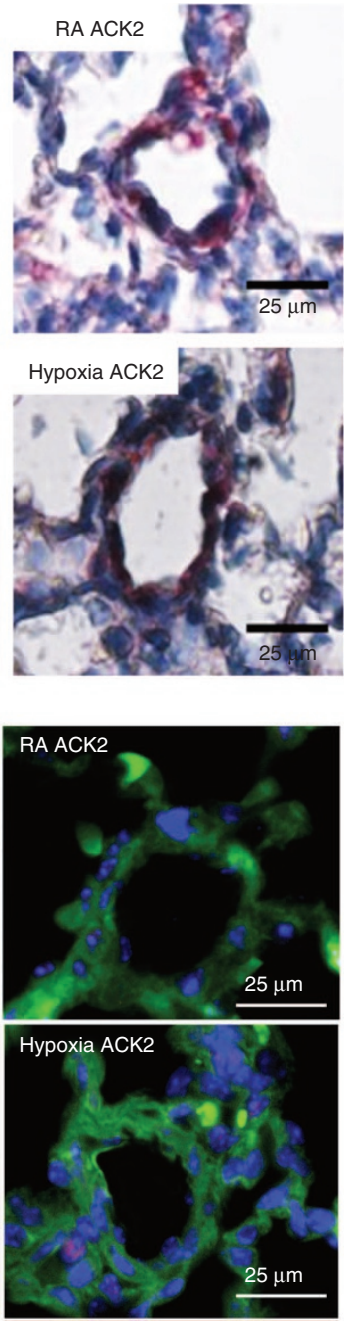

b

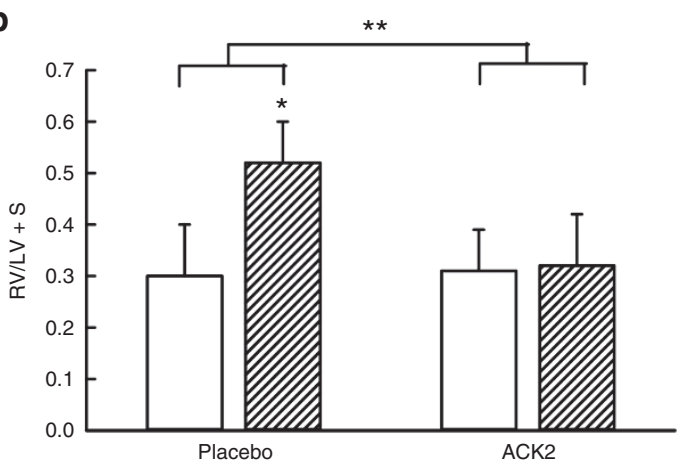

d

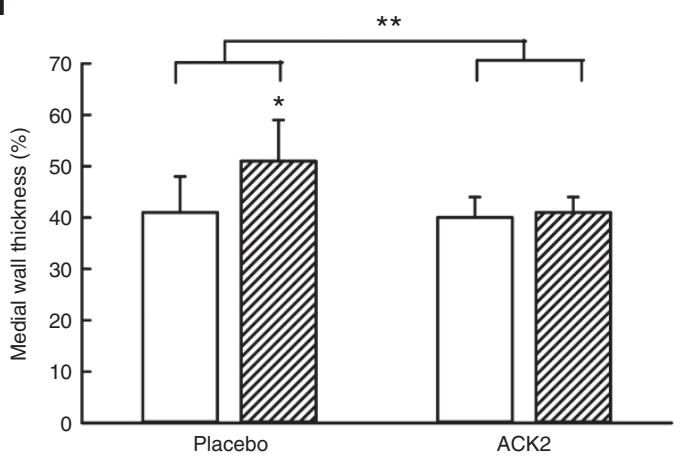

f

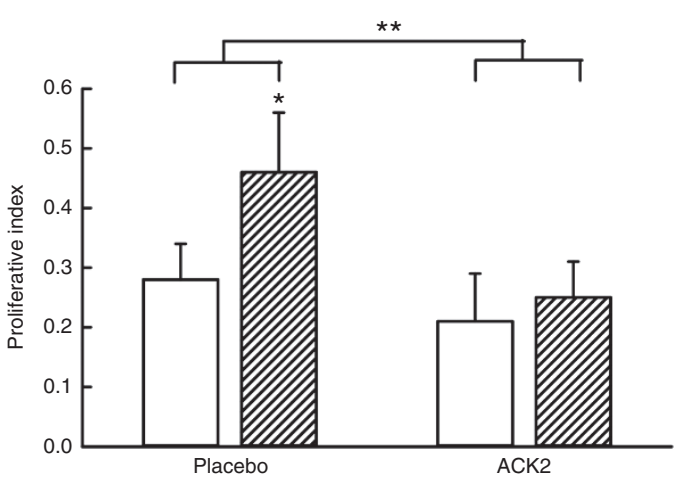

Figure 2. c-Kit neutralizing antibody (ACK2) attenuates neonatal chronic hypoxia-induced pulmonary hypertension. (a) Decreased RSVP in chronic hypoxic mice which received ACK2 $\left({ }^{*} P<0.0001\right.$ : RA vs. hypoxia-PL, ${ }^{*} P<0.02$ : hypoxia-PL vs. hypoxia-ACK2; $n=8-10 /$ group). White bars are RA and hatched bars are hypoxia. (b) Decreased right ventricular hypertrophy in hypoxic ACK2 mice $\left({ }^{*} P<0.001\right.$ : RA vs. hypoxia-PL, ${ }^{* *} P<0.01$ : hypoxia-PL vs. hypoxia-ACK2; $n=6-8 /$ group). (c) Decreased $\alpha$-smooth muscle actin (red) staining in the pulmonary vessels of ACK2-treated hypoxic mice. Original magnification $\times 400$. (d) Morphometric analysis performed on 35-40 (20-50 $\mu$ m diameter) pulmonary vessels ( $n=5 /$ group) demonstrated that ACK2 attenuated chronic hypoxia-induced pulmonary vascular remodeling ( ${ }^{*} P<0.05$ : RA vs. hypoxia-PL, ${ }^{* *} P<0.05$ : hypoxia-PL vs. hypoxia-ACK2). (e) Pulmonary vessels stained with anti-Ki67 antibody (red) and DAPI (blue). Ki67 pos cells (pink) were more abundantly present in the pulmonary vessels of hypoxia-PL mice as compared to hypoxic ACK2-treated mice. Original magnification $\times 400$. (f) Decreased percentage of Ki67 $7^{\text {pos }}$ cells in pulmonary vessels of hypoxic ACK2-treated mice. ( ${ }^{*} P<0.05$ : RA vs. hypoxia-PL, ${ }^{* *} P<0.04$ : hypoxia-PL vs. hypoxia-ACK2; $n=5$ /group). DAPI, 4',6-diamidino-2-phenylindole; $P L$, placebo; $\mathrm{RA}$, room air; RV/LV $+\mathrm{S}$, ratio of the weight of right ventricle to the left ventricle + septum; RVSP, right ventricular systolic pressure. 


\section{a}

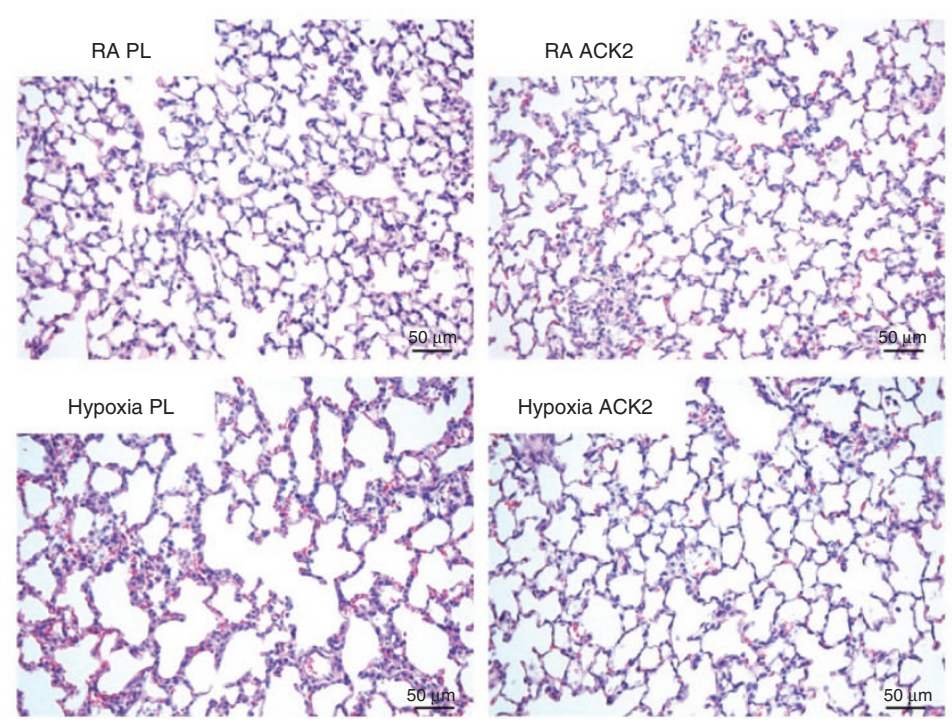

b

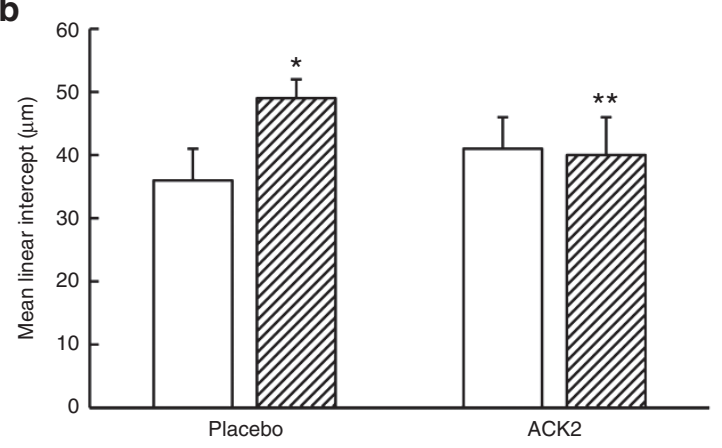

C

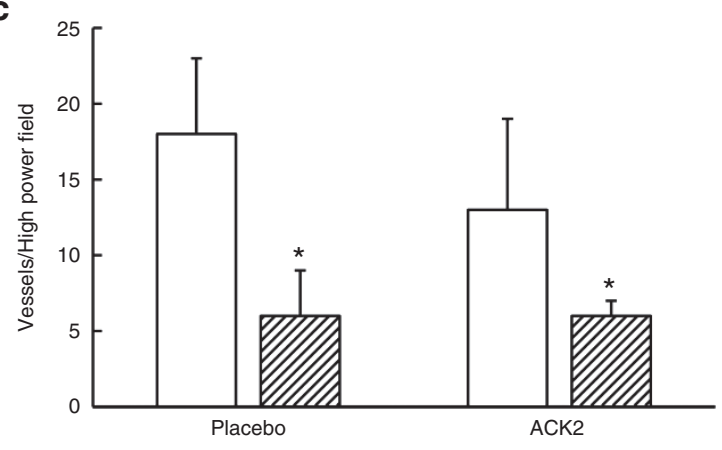

Figure 3. Effect of c-kit neutralizing antibody (ACK2) on lung alveolarization and angiogenesis. (a) H\&E-stained lung sections demonstrating improved alveolar structure in hypoxia-exposed mice treated with ACK2. Original magnification $\times 200$. Bar $=50 \mu \mathrm{m}$. (b) Decreased mean linear intercept in hypoxic ACK2 mice ( ${ }^{*} P<0.003$ : RA-PL vs. hypoxia-PL, ${ }^{*} P<0.03$ : hypoxia-PL vs. hypoxia-ACK2; $\left.n=5 / g r o u p\right)$. White bars are RA and hatched bars are hypoxia. (c) No difference in vascular density between hypoxic groups ( ${ }^{*} P<0.005$ : RA vs. hypoxia-PL or hypoxia- $\left.A C K 2\right)$. $P L$, placebo; $R A$, room air.

study, we demonstrate c-kit-positive cells in the endothelium, media, and adventitia of remodeled pulmonary vessels and western blot analysis of protein homogenates obtained from pulmonary arterioles demonstrated increased phosphorylated c-kit and SCF expression. This present finding is in keeping with prior data which demonstrated that hypoxia-inducible factor directly enhances the transcriptional activity of SCF and c-kit in response to hypoxia in tumor cell lines (20).

This hypoxia-induced enhanced c-kit and SCF expression is important in promoting angiogenesis following organ injury (21) and augmentation of SCF/c-kit signaling has been shown to improve organ repair by increasing angiogenesis (22). Interestingly, we did not find a significant effect of SCF/c-kit signaling on pulmonary angiogenesis during hypoxia-induced $\mathrm{PH}$. We however speculate that the increased c-kit expression noted in the pulmonary arteries of neonatal mice with chronic hypoxia-induced $\mathrm{PH}$ was an adaptive effect to increase perfusion to the pulmonary vascular wall and this response may have become maladaptive and promoted pulmonary vascular cell proliferation and remodeling. This is consistent with data published by Wang et al., who demonstrated significant SCFinduced proliferation of aortic vascular smooth muscle cells (15) and decreased proliferation of aortic smooth muscle cells following femoral artery wire injury in c-kit and SCF mutant mice.

In our present study, we also show that abrogation of SCF/c-kit signaling decreased pulmonary vascular cell proliferation and this was accompanied by decreased activation of the ERK1/2 pathway. This is intriguing as p42/p44 ERK, a member of the mitogen-activated protein kinase super family, has been previously shown to be upregulated in hypoxic lungs and to mediate pulmonary vascular cell proliferation (18). Surprisingly, further questioning to elucidate the cellular population which had increased ERK1/2 activation revealed that isolated neonatal PASM cells express c-kit and they increased their proliferation and ERK1/2 activation following SCF stimulation. This was unexpected as other studies have not demonstrated c-kit expression on PASM cells, but rather their expression on native pulmonary vasculature cells was mainly restricted to endothelial cells (23). It is possible that the variability in c-kit expression may be due to differences in the species studied as well as the developmental stage at the time of evaluation. Nonetheless, our finding is consistent with those of Davis et al. who also showed that c-kit is expressed on adult PASM cells (24). 


\section{Articles | Younget al.}

a

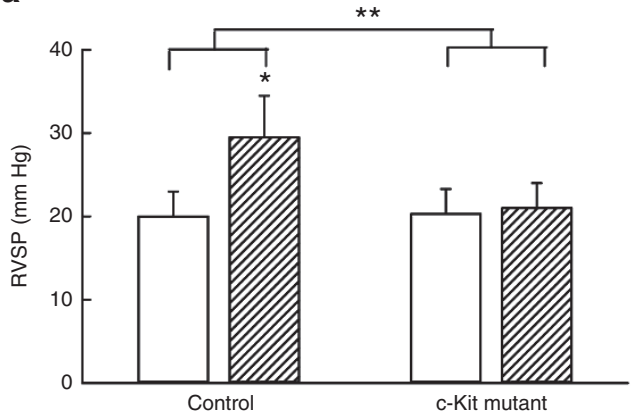

C

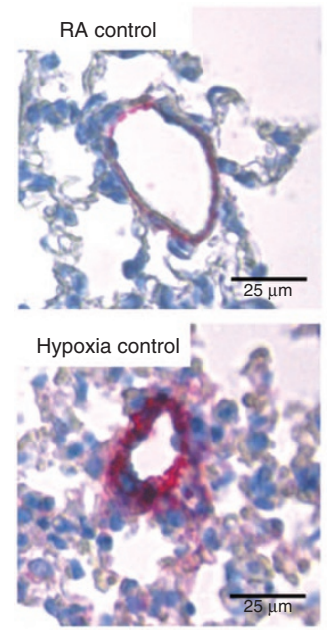

e

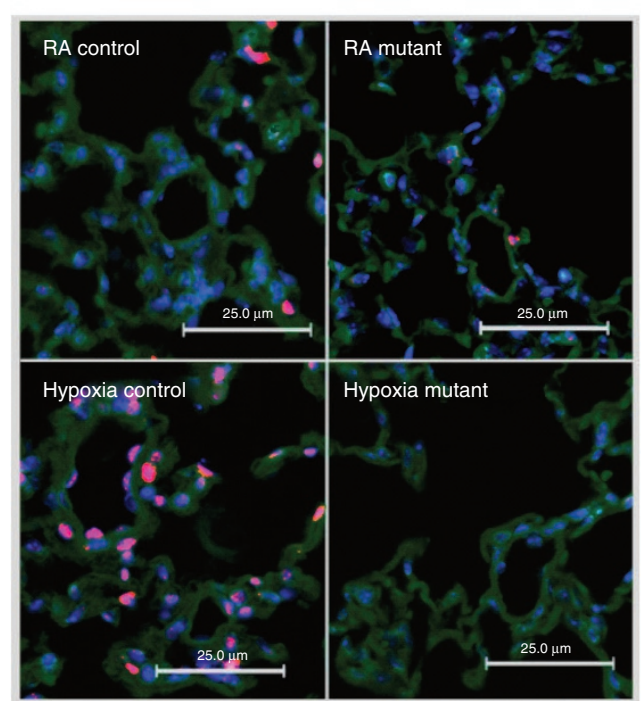

b

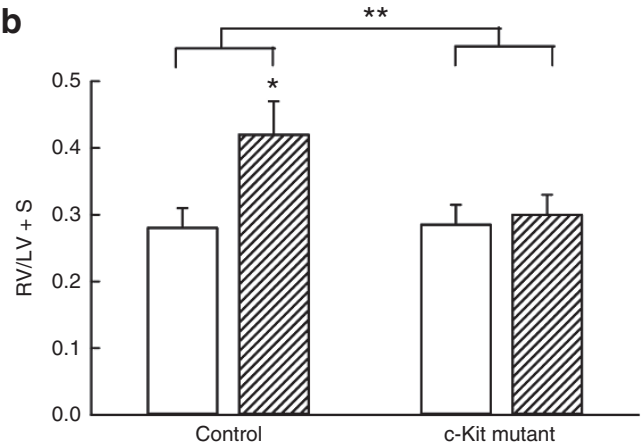

d

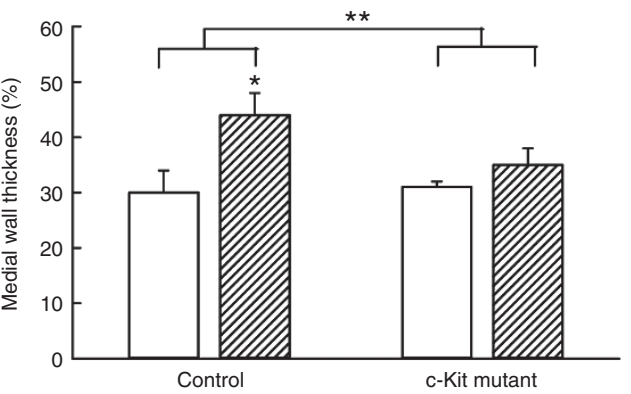

f

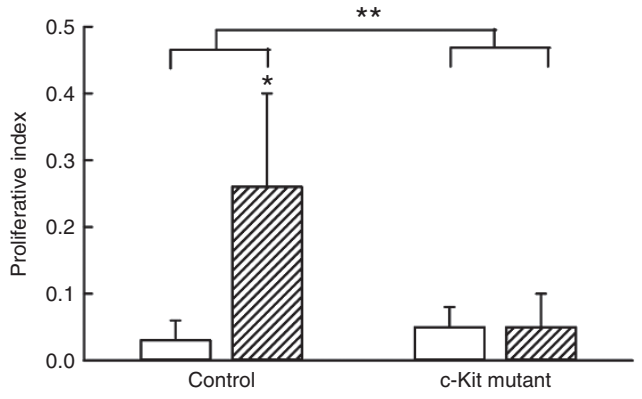

Figure 4. Neonatal c-kit mutant mice have decreased pulmonary hypertension. (a) Lower RSVP in hypoxic neonatal c-kit mutant mice compared to control hypoxic mice $\left({ }^{*} P<0.001\right.$ : RA control vs. hypoxia control, ${ }^{* *} P<0.01$ : hypoxia control vs. hypoxia mutant; $n=10 /$ group $)$. White bars are RA and hatched bars are hypoxia. (b) Less right ventricular hypertrophy in hypoxic neonatal c-kit mutant mice compared to control hypoxic mice $\left({ }^{*} P<0.001:\right.$ RA control vs. hypoxia control, ${ }^{* *} P<0.005$ : hypoxia control vs. hypoxia mutant; $n=10 /$ group). (c) Lung sections stained with $\alpha$-smooth muscle actin (red) demonstrating decreased pulmonary vascular muscularization in the chronically hypoxic c-kit mutant mice as compared to the control hypoxic mice. Original magnification $\times 400$. Bar $=25 \mu \mathrm{m}$. (d) Chronically hypoxic c-kit mutant mice had decreased medial wall thickness as compared to control hypoxic mice, $\left({ }^{*} P<0.001\right.$ : RA control vs. hypoxia control, ${ }^{* *} P<0.01$ : hypoxia control vs. hypoxia mutant; $n=5 /$ group). (e) Pulmonary vessels stained with anti-Ki67 antibody (red) and 4,6-diamidino-2-phenylindole (blue). Ki67 pos cells (pink) were more abundantly present in the pulmonary vessels of control hypoxic mice as compared to hypoxic c-kit mutant mice. Original magnification $\times 400$. Bar $=25 \mu \mathrm{m}$. (f) Increased percentage of Ki67 ${ }^{\text {pos }}$ cells in the pulmonary vessels of control hypoxic mice as compared to hypoxic c-kit mutant mice, $\left({ }^{*} P<0.001\right.$ : RA control vs. hypoxia control, ${ }^{*} P<0.03$ : hypoxia control vs. hypoxia mutant; $n=5$ /group). RA, room air; RV/LV $+\mathrm{S}$, ratio of the weight of right ventricle to the left ventricle + septum; RVSP, right ventricular systolic pressure. 
a

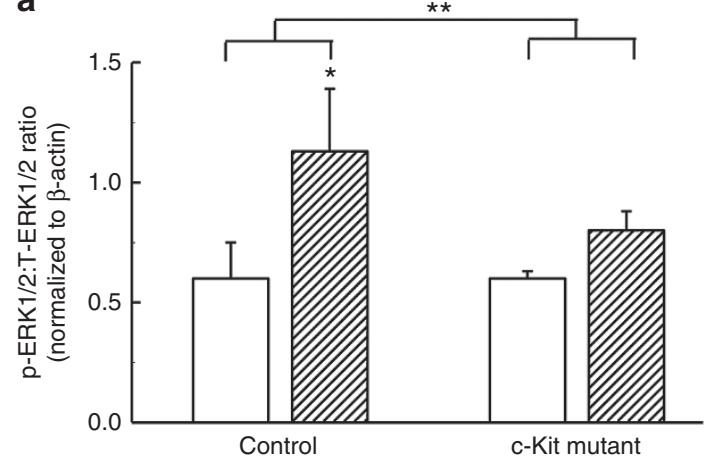

b

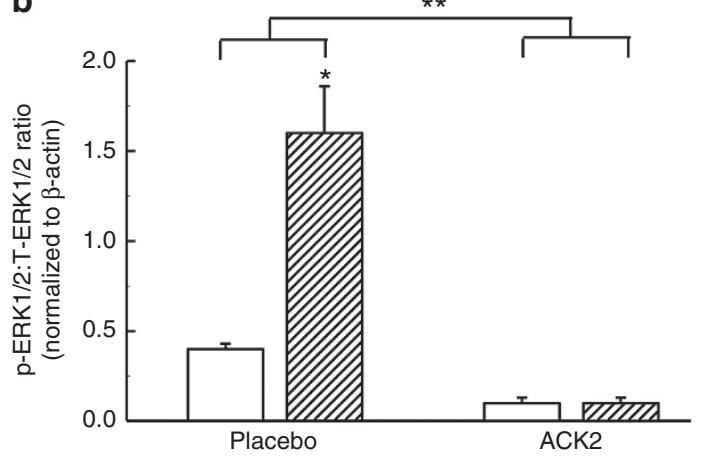

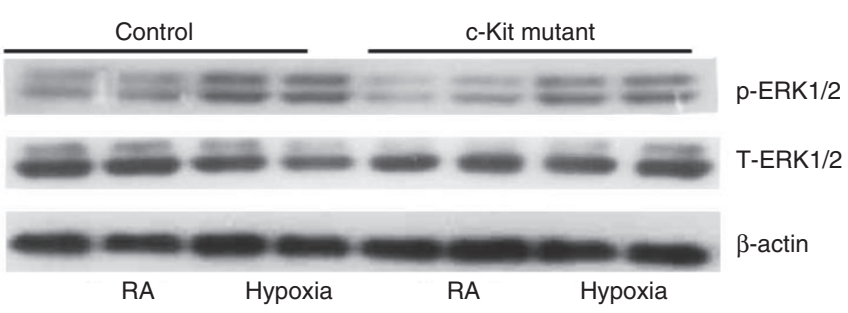

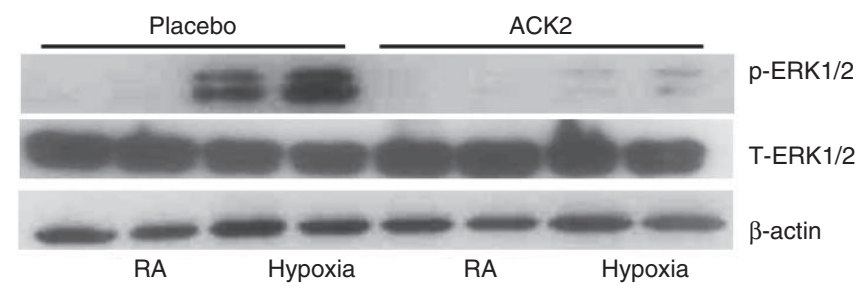

Figure 5. c-Kit regulates ERK1/2 activation. (a) Increased lung $p$-ERK1/2 activation in hypoxic control mice as compared of c-kit mutant mice $(* P<0.001$ : RA control vs. hypoxia control, ${ }^{* *} P<0.02$ : hypoxia control vs. hypoxia mutant; $n=5 /$ group). White bars are RA and hatched bars are hypoxia. $p$-ERK1/2 and T-ERK1/2 expression are normalized to $\beta$-actin. (b) Hypoxic ACK2 mice had decreased lung p-ERK1/2 activation as compared to hypoxic PL mice ( ${ }^{*} P<0.001$ : RA-PL vs. hypoxia-PL, ${ }^{* *} P<0.003$ : hypoxia-PL vs. hypoxia-ACK2; $n=5$ /group). PL, placebo; RA, room air.

Finally, it is important to mention the limitations of this study. c-Kit is present on several lung cells and thus its effects may not be localized to the pulmonary vascular bed. Indeed, studies in our laboratory have revealed an important role for c-kit in lung angiogenesis and alveolarization. Unexpectedly, in this present study, ACK2-treated hypoxic mice not only had an improvement in $\mathrm{PH}$ but they had better alveolar structure as compared to hypoxia-PL mice. Further studies will however be needed to delineate dose and temporal related effects as there was a trend towards a decrease in lung alveolarization and angiogenesis in the normoxic ACK2-treated mice. In addition, while the attenuation in pulmonary vascular remodeling evidenced following inhibition of SCF/c-kit signaling maybe potentially due to decreased ERK1/2 activation, we recognize that some of the PASM cells utilized in our in vitro studies may have been obtained from conduit vessels and their exact role in $\mathrm{PH}$ is unclear. We also acknowledge that some populations of c-kit-positive cells in the pulmonary vasculature are progenitor cells and these cells may potentiate vascular remodeling by either differentiating into myofibroblasts or secreting mitogenic factors. It is also possible that the reduction in $\mathrm{RVH}$ evidenced following c-kit antagonism was not entirely due to the improvement in $\mathrm{PH}$ but rather a direct effect of c-kit on myocardial mitogenesis.

Our present study however provides distinct and new evidence of the mechanistic role of SCF/c-kit signaling in the pathogenesis of chronic hypoxia-induced pulmonary vascular remodeling. We demonstrate in vivo and in vitro the functional relevance of $\mathrm{SCF} / \mathrm{c}$-kit signaling in $\mathrm{PH}$ and we show that activation of SCF/c-kit signaling potentiates PASM cell proliferation and this is accompanied by ERK1/2 activation. We therefore speculate that future investigations evaluating novel strategies to inhibit SCF/c-kit receptor signaling may provide innovative therapies to attenuate chronic hypoxia-induced pulmonary vascular remodeling.

\section{METHODS}

\section{Materials}

Pregnant FVB/NJ mice, WBB6F1-Kit ${ }^{W-v /+}$, were obtained from Jackson Laboratories (Bal Harbor, ME). Primary antibodies utilized were: c-kit (1:50; DAKO, Carpinteria, CA), SCF (1:500; Abcam, Cambridge, MA), $\alpha$-smooth muscle actin (1:500; Sigma-Aldrich, St. Louis, MO), von Willebrand factor (vWF: 1:200; DAKO), and Ki67 (1:100; Abcam). Secondary antibodies utilized were: biotinylated anti-mouse IgG (1:200; Vector, Burlingame, CA), horseradish peroxidase-conjugated Donkey Anti-Goat IgG (1:2,000; Jackson Immunoresearch, West Grove, PA), Goat Anti-Mouse IgG Alkaline Phosphatase (1:100; Sigma-Aldrich), and Goat Anti-Rabbit IgGPeroxidase (1:100; Sigma-Aldrich). Mouse c-kit neutralizing antibody (ACK2; $50 \mu \mathrm{g} / \mathrm{kg}$ ) and recombinant SCF were both obtained from eBioscience (San Diego, CA). FR180204 (a selective ERK1/2 antagonist) was obtained from Santa Cruz Biotechnology (Santa Cruz, CA).

\section{Animal Care and Treatment}

All animal experiments were performed according to guidelines set forth by the University of Miami Miller School of Medicine Animal Care and Use Committee. In the first set of studies, neonatal c-kit mutant mice (WBB6F1-Kit ${ }^{\mathrm{W}-v /+}$ ) as well as their wild-type controls $(n=22 /$ group $)$ were exposed to normobaric hypoxia $\left(\mathrm{FiO}_{2}=0.12\right)$ 


\section{Articles | Young et al.}

a

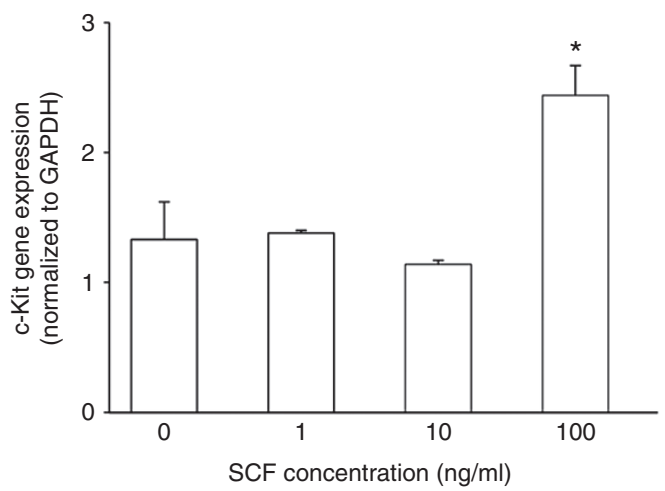

C

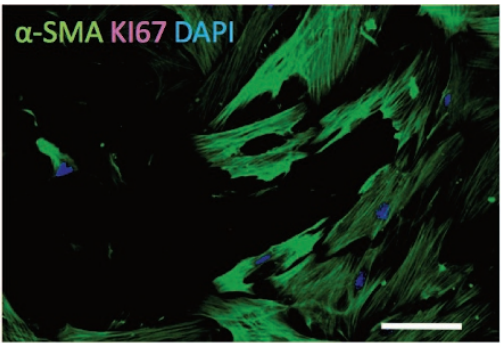

d

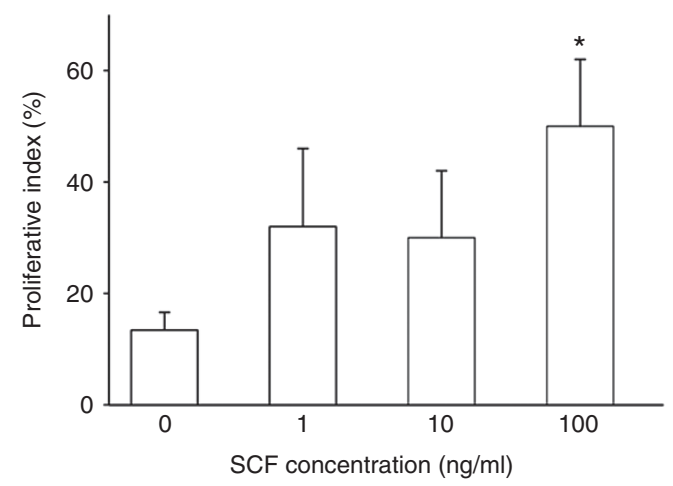

b
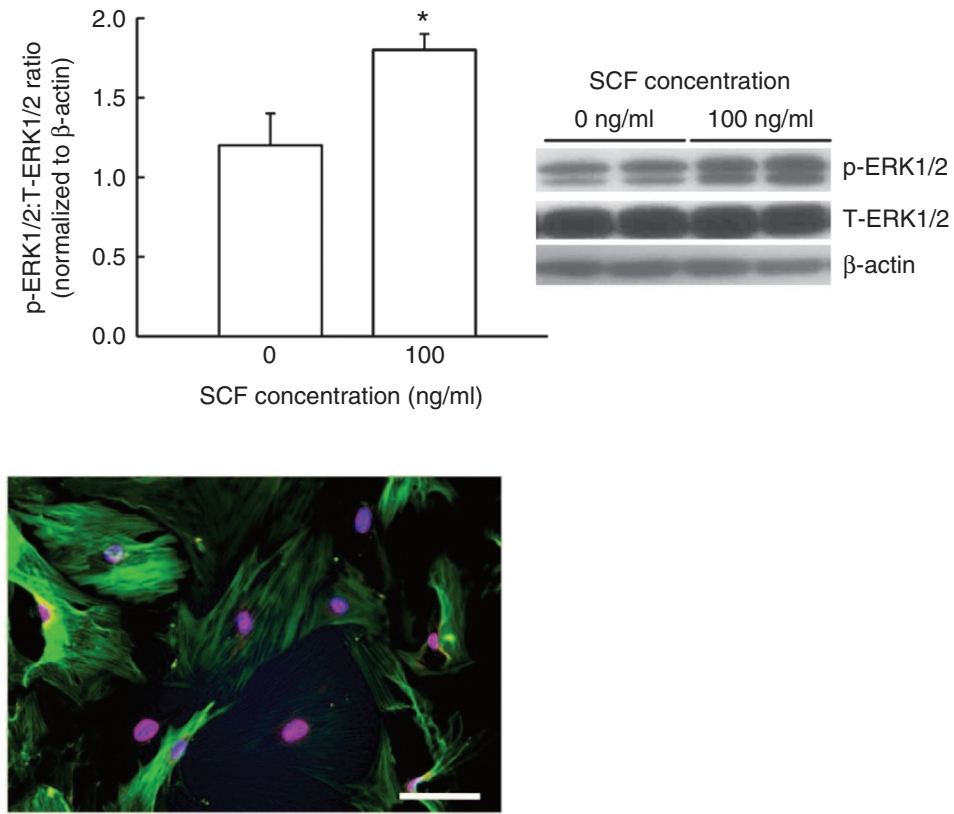

e

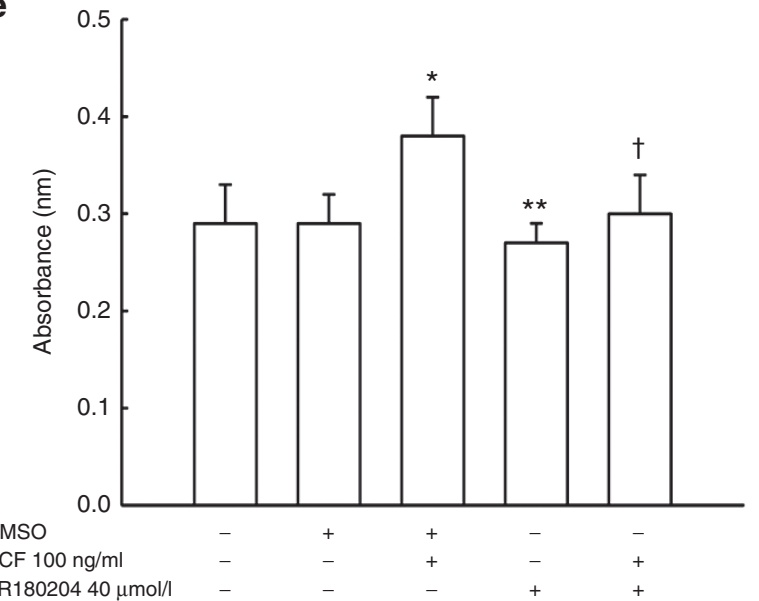

Figure 6. SCF stimulates pulmonary artery smooth muscle (PASM) cell proliferation. (a) c-Kit mRNA expression in neonatal PASM cells exposed to varying doses of SCF. c-Kit transcripts were detected in unstimulated neonatal PASM cells and these transcripts increased following exposure to SCF $100 \mathrm{ng} / \mathrm{ml}$ $(* P<0.03:$ SCF $0 \mathrm{ng} / \mathrm{ml}$ vs. SCF $100 \mathrm{ng} / \mathrm{ml} ; n=4 / \mathrm{group})$. (b) Increased $\mathrm{p}$-ERK $1 / 2$ activation in PASM exposed to SCF $100 \mathrm{ng} / \mathrm{ml}\left({ }^{*} P<0.04: \mathrm{SCF} 0 \mathrm{ng} / \mathrm{ml}\right.$ vs. SCF $100 \mathrm{ng} / \mathrm{ml} ; n=4 /$ group). p-ERK1/2 and T-ERK1/2 expression are normalized to $\beta$-actin. (c) Ki67 pos (pink) cells in untreated PASM cells (left panel) and cells exposed to SCF $100 \mathrm{ng} / \mathrm{ml}$ (right panel). Original magnification $\times 400$. Bar $=50 \mu \mathrm{m}$. (d) Increased percentage of Ki67 ${ }^{\text {pos }}$ cells in neonatal PASM cells exposed to SCF $100 \mathrm{ng} / \mathrm{ml}\left({ }^{*} P<0.05:\right.$ SCF $\left.0 \mathrm{ng} / \mathrm{ml} \mathrm{vs.} \mathrm{SCF} 100 \mathrm{ng} / \mathrm{ml} ; n=4 / \mathrm{group}\right)$. (e) Neonatal PASM cells which were pretreated with vehicle and exposed to SCF $100 \mathrm{ng} / \mathrm{ml}$ had increased BrdU incorporation $(* P<0.007$ : DMSO vs. DMSO + SCF $100 \mathrm{ng} / \mathrm{ml}$ ). Exposure of PASM to FR180204 alone suppressed BrdU incorporation $\left({ }^{* *} P<0.001\right.$ : DMSO + SCF $100 \mathrm{ng} / \mathrm{ml}$ vs. FR180204). SCF- exposed PASM cells which were pretreated with the ERK1/2 antagonist had suppressed BrdU incorporation ( ${ }^{+} P<0.002$ : DMSO + SCF $100 \mathrm{ng} / \mathrm{ml}$ vs. FR180204 + SCF $\left.100 \mathrm{ng} / \mathrm{ml}\right)$. DAPI, 4',6-diamidino-2-phenylindole; DMSO, dimethyl sulfoxide; GAPDH, glyceraldehyde 3-phosphate dehydrogenase; SMA, smooth muscle actin; SCF, stem cell factor.

or normoxia $\left(\mathrm{RA} ; \mathrm{FiO}_{2}=0.21\right)$ for $2 \mathrm{wk}$. In the second set of studies, $\mathrm{FVB} / \mathrm{NJ}$ neonatal mice (1-2 d old; $n=26$ ) were exposed to normobaric hypoxia $\left(\mathrm{FiO}_{2}=0.12\right)$ or normoxia $\left(\mathrm{RA} ; \mathrm{FiO}_{2}=0.21\right)$ for two wk. After $1 \mathrm{wk}$ of this exposure, the mice were randomly assigned to receive daily i.p. injections of normal saline (PL; $n=15$ ) or anti-c-kit antibody (ACK2; $50 \mu \mathrm{g} / \mathrm{kg} ; n=11$ ) for $7 \mathrm{~d}$, from postnatal day $7-14$. The dose and frequency of dosing was based on a prior study (25). The $\mathrm{FiO}_{2}$ utilized in this neonatal study was based on previous studies which demonstrated increased mortality of the mice if lower $\mathrm{FiO}_{2}$ or a longer duration of exposure were utilized (26).

\section{Assessment of $\mathrm{PH}$}

RVSP was measured and continuously recorded on a Gould polygraph (model TA-400; Gould Instruments, Cleveland, $\mathrm{OH}$ ) as previously described with minor modifications (27). RVH was assessed by measuring the $\mathrm{RV} / \mathrm{LV}+\mathrm{S}$.

\section{Lung Morphometric Analysis}

Lung perfusion was performed as previously described (28). Serial paraffin-embedded lung sections $5 \mu \mathrm{m}$ thick were stained with antibodies against $\alpha$ - $\alpha$-smooth muscle actin (clone 1A4; Sigma-Aldrich) 
and vWF (DAKO). The medial wall thickness of fully muscular intraacinar pulmonary vessels was determined using the formula: 2 MT $\times 100 / \mathrm{ED}$ where MT is the distance between internal and external elastic laminae and ED is the external diameter. Approximately 35-40 arteries were evaluated per slide and all morphometric analyses were performed by a blinded observer. The number of proliferating pulmonary vascular cells was determined by staining lung sections with $\mathrm{Ki67}$, a marker of cell proliferation. The proliferation index was calculated by the following formula: (No. of Ki67 pos cells/No. of Ki67 ${ }^{\text {pos }}+$ No. of Ki67 neg cells per pulmonary vessel). Alveolarization was determined by measuring the mean linear intercept as previously described (29). Images from five randomly selected, nonoverlapping parenchymal fields were acquired from lung sections of each animal $(n=5 /$ group) at $\times 20$ magnification. Lung vascular density was determined by counting the number of vWF positive ( $\left.\mathrm{vWF}^{\mathrm{pos}}\right)$ blood vessels/highpower field (20-50 $\mu \mathrm{m}$ in diameter). Five randomly selected, nonoverlapping parenchymal fields were evaluated from lung sections of each animal ( $n=5 /$ group) by a blinded observer.

\section{PASM Cell Culture}

The segmental and subsegmental branches of the right and left pulmonary arteries (third and fourth generation) were dissected free of surrounding tissue. The arteries were then minced, washed with phosphate-buffered saline, and digested with collagenase. Digested arteries were incubated in Dulbecco's modified Eagle's medium/F12 supplemented with penicillin $(100 \mathrm{U} / \mathrm{ml})$, streptomycin $(10 \mu \mathrm{g} / \mathrm{ml})$, and $10 \%$ fetal bovine serum until cell proliferation was evident. PASM cells were identified by their characteristic hill-and-valley morphology and $>99 \%$ positive immunostaining for calponin and $\alpha$-smooth muscle actin. This was taken as evidence that cultures were not contaminated with fibroblasts or endothelial cells. PASM cells (passages $2-4)$ were seeded on 96-well plates $\left(1 \times 10^{4}\right.$ cells/well $)$ and cultured for $24 \mathrm{~h}$ in Dulbecco's modified Eagle's medium/F-12 containing $10 \%$ fetal bovine serum. In order to render the cells quiescent, they were serum starved for $48 \mathrm{~h}$ with Dulbecco's modified Eagle's medium/F-12 containing $0.5 \%$ fetal bovine serum. Cells were then exposed to the specific ERK1/2 antagonist, FR180204 $40 \mu \mathrm{mol} / \mathrm{l}$ or dimethyl sulfoxide (vehicle) for $1 \mathrm{~h}$ followed by a 72 -h incubation period with SCF $(0$ and $100 \mathrm{ng} / \mathrm{ml})$. The latter dose of SCF was chosen as pilot experiments in our laboratory revealed that lower doses of SCF had no effect on cell proliferation. All treatments were done in duplicate and all experiments were repeated four times.

\section{PASM Cell Proliferation}

PASM cell proliferation was determined by the BrdU Colorimetric ELISA assay according to the manufacturer instructions (Roche Applied Science, Indianapolis, IN).

\section{Real-Time Reverse Transcription-PCR}

Total RNA was extracted from neonatal PASM cells following exposure to $0,1,10$, and $100 \mathrm{ng} / \mathrm{ml} \mathrm{SCF}$ as previously described (30). The gene expression of c-kit and glyceraldehyde 3-phosphate dehydrogenase was quantified by real-time reverse transcription-PCR using Real-Time Gene Expression Assay (Applied Biosystems, Carlsbad, $\mathrm{CA}$ ). The relative quantity of c-kit was normalized to glyceraldehyde 3-phosphate dehydrogenase.

\section{Western Blot}

The protein expression of c-kit, SCF, ERK1/2, p-ERK1/2, and $\beta$-actin in pulmonary artery homogenates was determined by western blot analysis as previously described (27). Band intensity was quantified with Quantity One software (Bio-Rad, CA).

\section{Immunohistochemistry and Immunofluorescence}

Paraffin-embedded lung sections were deparaffinized and rehydrated. Following antigen retrieval, endogenous peroxidase in the lung sections was blocked by incubating for $45 \mathrm{~min}$ with $0.3 \% \mathrm{H}_{2} \mathrm{O}_{2}$ in methanol. Samples were washed and incubated for $1 \mathrm{~h}$ at room temperature with $10 \%$ donkey serum to saturate any nonspecific binding sites of the antibodies, followed by overnight incubation at $4{ }^{\circ} \mathrm{C}$ with appropriate primary antibodies. After washing, the sections were incubated with the appropriate secondary antibodies at room temperature. Fluorescent signals were enhanced by using a tyramide signal amplification kit (Perkin Elmer, Waltham, MA) according to manufacturers' instructions and sections were evaluated under a Zeiss Confocal Microscope (model LSM-510; Carl Zeiss Microimaging, Thornwood, NY).

\section{Statistics}

All results are reported as mean $\pm \mathrm{SD}$. Data were analyzed by ANOVA followed by a post hoc analysis (Holm-Sidak). Values of $P<0.05$ were considered statistically significant. Statistical analysis was performed using SigmaStat software (SyStat Software, San Jose, CA).

\section{STATEMENT OF FINANCIAL SUPPORT}

This study was supported by National Institute of Health Career Development Award, Bethesda, MD and Batchelor Research Foundation Award, Miami, FL (to K.C.Y.) and University of Miami Project New Born.

Disclosure: The authors declare no conflict of interest.

\section{REFERENCES}

1. Stenmark KR, Fagan KA, Frid MG. Hypoxia-induced pulmonary vascular remodeling: cellular and molecular mechanisms. Circ Res 2006;99:675-91.

2. Bernex F, De Sepulveda P, Kress C, Elbaz C, Delouis C, Panthier JJ. Spatial and temporal patterns of c-kit-expressing cells in WlacZ/+ and WlacZ/ WlacZ mouse embryos. Development 1996;122:3023-33.

3. Ashman LK, Cambareri AC, To LB, Levinsky RJ, Juttner CA. Expression of the YB5.B8 antigen (c-kit proto-oncogene product) in normal human bone marrow. Blood 1991;78:30-7.

4. Papayannopoulou T, Brice M, Broudy VC, Zsebo KM. Isolation of c-kit receptor-expressing cells from bone marrow, peripheral blood, and fetal liver: functional properties and composite antigenic profile. Blood 1991;78:1403-12.

5. Hollenbeck ST, Sakakibara K, Faries PL, Workhu B, Liu B, Kent KC. Stem cell factor and c-kit are expressed by and may affect vascular SMCs through an autocrine pathway. J Surg Res 2004;120:288-94.

6. Besmer P. The kit ligand encoded at the murine Steel locus: a pleiotropic growth and differentiation factor. Curr Opin Cell Biol 1991;3:939-46.

7. Reber L, Da Silva CA, Frossard N. Stem cell factor and its receptor c-Kit as targets for inflammatory diseases. Eur J Pharmacol 2006;533:327-40.

8. Lammie A, Drobnjak M, Gerald W, Saad A, Cote R, Cordon-Cardo C. Expression of c-kit and kit ligand proteins in normal human tissues. J Histochem Cytochem 1994;42:1417-25.

9. Davie NJ, Crossno JT Jr, Frid MG, et al. Hypoxia-induced pulmonary artery adventitial remodeling and neovascularization: contribution of progenitor cells. Am J Physiol Lung Cell Mol Physiol 2004;286:L668-78.

10. Crossno JT Jr, Garat CV, Reusch JE, et al. Rosiglitazone attenuates hypoxiainduced pulmonary arterial remodeling. Am J Physiol Lung Cell Mol Physiol 2007;292:L885-97.

11. Montani D, Perros F, Gambaryan N, et al. C-Kit-positive cells accumulate in remodeled vessels of idiopathic pulmonary arterial hypertension. Am J Respir Crit Care Med 2011;184:116-23.

12. Ashman LK. The biology of stem cell factor and its receptor C-kit. Int J Biochem Cell Biol 1999;31:1037-51.

13. Matsui J, Wakabayashi T, Asada M, Yoshimatsu K, Okada M. Stem cell factor/c-kit signaling promotes the survival, migration, and capillary tube formation of human umbilical vein endothelial cells. J Biol Chem 2004;279:18600-7.

14. Wang CH, Anderson N, Li SH, et al. Stem cell factor deficiency is vasculoprotective: unraveling a new therapeutic potential of imatinib mesylate. Circ Res 2006;99:617-25.

15. Wang CH, Verma S, Hsieh IC, et al. Stem cell factor attenuates vascular smooth muscle apoptosis and increases intimal hyperplasia after vascular injury. Arterioscler Thromb Vasc Biol 2007;27:540-7.

16. Ghofrani HA, Seeger W, Grimminger F. Imatinib for the treatment of pulmonary arterial hypertension. N Engl J Med 2005;353:1412-3.

17. Jin N, Hatton N, Swartz DR, et al. Hypoxia activates jun-N-terminal kinase, extracellular signal-regulated protein kinase, and p38 kinase in pulmonary arteries. Am J Respir Cell Mol Biol 2000;23:593-601.

18. Das M, Bouchey DM, Moore MJ, Hopkins DC, Nemenoff RA, Stenmark KR. Hypoxia-induced proliferative response of vascular adventitial 


\section{Articles $\mid$ Youngetal.}

fibroblasts is dependent on g protein-mediated activation of mitogen-activated protein kinases. J Biol Chem 2001;276:15631-40.

19. Frid MG, Li M, Gnanasekharan M, et al. Sustained hypoxia leads to the emergence of cells with enhanced growth, migratory, and promitogenic potentials within the distal pulmonary artery wall. Am J Physiol Lung Cell Mol Physiol 2009;297:L1059-72.

20. Han ZB, Ren H, Zhao H, et al. Hypoxia-inducible factor (HIF)-1 alpha directly enhances the transcriptional activity of stem cell factor (SCF) in response to hypoxia and epidermal growth factor (EGF). Carcinogenesis 2008;29:1853-61.

21. Sun L, Lee J, Fine HA. Neuronally expressed stem cell factor induces neural stem cell migration to areas of brain injury. J Clin Invest 2004;113: 1364-74.

22. Xiang FL, Lu X, Hammoud L, et al. Cardiomyocyte-specific overexpression of human stem cell factor improves cardiac function and survival after myocardial infarction in mice. Circulation 2009;120:1065-74, 9 p following 1074 .

23. Suzuki T, Suzuki S, Fujino N, et al. c-Kit immunoexpression delineates a putative endothelial progenitor cell population in developing human lungs. Am J Physiol Lung Cell Mol Physiol 2014;306:L855-65.

24. Davis BN, Hilyard AC, Nguyen PH, Lagna G, Hata A. Induction of microRNA-221 by platelet-derived growth factor signaling is criti- cal for modulation of vascular smooth muscle phenotype. J Biol Chem 2009;284:3728-38.

25. Okura M, Maeda H, Nishikawa S, Mizoguchi M. Effects of monoclonal anti-c-kit antibody (ACK2) on melanocytes in newborn mice. J Invest Dermatol 1995;105:322-8.

26. Ambalavanan N, Bulger A, Murphy-Ullrich J, Oparil S, Chen YF. Endothelin-A receptor blockade prevents and partially reverses neonatal hypoxic pulmonary vascular remodeling. Pediatr Res 2005;57(5 Pt 1):631-6.

27. Young KC, Torres E, Hatzistergos KE, Hehre D, Suguihara C, Hare JM. Inhibition of the SDF-1/CXCR4 axis attenuates neonatal hypoxia-induced pulmonary hypertension. Circ Res 2009;104:1293-301.

28. Bellodi C, Lidonnici MR, Hamilton A, et al. Targeting autophagy potentiates tyrosine kinase inhibitor-induced cell death in Philadelphia chromosome-positive cells, including primary CML stem cells. J Clin Invest 2009;119:1109-23.

29. Miranda LF, Rodrigues CO, Ramachandran S, et al. Stem cell factor improves lung recovery in rats following neonatal hyperoxia-induced lung injury. Pediatr Res 2013;74:682-8.

30. Wu S, Peng J, Duncan MR, Kasisomayajula K, Grotendorst G, Bancalari E. ALK-5 mediates endogenous and TGF-beta1-induced expression of connective tissue growth factor in embryonic lung. Am J Respir Cell Mol Biol 2007;36:552-61. 